\title{
MiR-223 down-regulates RHOB to inhibit progression of papillary thyroid cancer
}

Wei Zhang

Shengjing Hospital of China Medical University

Wenyue Ji

Shengjing Hospital of China Medical University

Xudong Zhao ( $\sim$ zhaoxdent@hotmail.com )

Shengjing Hospital of China Medical University https://orcid.org/0000-0002-6949-2555

\section{Research article}

Keywords: miR-223, Ras homolog gene family, member B, papillary thyroid cancer, mircroRNA

Posted Date: December 12th, 2019

DOI: https://doi.org/10.21203/rs.2.18711/v1

License: (1) This work is licensed under a Creative Commons Attribution 4.0 International License. Read Full License 


\section{Abstract}

Backgrounds The incidence of thyroid carcinoma continues to increase every year. The incidence of papillary thyroid carcinoma (PTC) is the largest of all thyroid cancers, and is the most widely seen. Thus, Do some identification and testing of biomarkers related to tumorigenesis and development, which will help understand and treat PTC.

Methods The expression of miR-223 and RHOB needs to be detected by polymerase chain reaction and western blot, respectively. Thyroid cell-line BCPAP and K1 cells were cultured, transfected for overexpression of miR-223or RHOB, and evaluated using MTT, Transwell, and apoptosis assays. In order to better understand the relationship between miR-223 and RHOB, dual luciferase reporter gene detection and $\mathrm{RHOB}$ rescue experiments were performed. In addition, clinical pathological parameters and correlation analysis of patients with miR-223 were also performed.

Results Aberrant expression of miR-223 was detected in PTC samples. We also determined that miR-223 expression was associated with TNM staging and cervical metastasis. Moreover, miR-223 inhibits the increase in cell number and position, as well as defense against cancer cells and accelerates cell death. Furthermore, miR-223 excessive expression was associated with a significant inhibition of RHOB levels. According to the luciferase test report, it can be known miR-223 was able to bind RHOB 3'-UTR, it is possible to change its stability through these, and finally achieve the purpose of reducing RHOB. Finally,excessive expression of RHOB has undergone earth-shaking changes in the effect of miR-223 overexpression on cell number growth, invasion and disappearance.

Conclusion Aberrant miR-223/RHOB expression took part in PTC make headway and miR-223 inhibition caused RHOB overexpression and cancer progression. Therefore, miR-223 may be a potential therapeutic target for PTC.

\section{Background}

The incidence of thyroid cancer has also become higher and higher, but the incidence of thyroid papillary cancer (PTC) has been ranked first [1]. In addition, the fifth most common tumor in women is PTC [2, 3]. The biological behavior of different PTCs varies widely. Some exhibit few clinical symptoms while others are aggressive and may be fatal. This phenomenon is associated with different genetic abnormalities [4]. Therefore, Do some identification and testing of biomarkers related to tumorigenesis and development, which will help understand and treat PTC.

Microrna (miRNAs) are a class of non-coding rna that can be directly contacted with the 3 '-untranslation region (3'-UTRs) of a gene to affect the expression of a protein-coding gene[5, 6]. Coding for this gene the miRNA miR-223 in humans is on the $X$ chromosome to q12 this site[7]. Recently, miR-223 phenotypes have been reported in both hematological malignancies [8-12] and in solid tumors, such as breast cancer $[13,14]$, gastric cancer $[15,16]$, hepatic cancer $[17,18]$, and colon cancer [19-21]. However, what kind of function does miR-223 have in PTC? We still have no way to understand.In present study, PicTar, 
MiRanda and targetscan were used together to predict the targets of miR-223. RHOB was found to be as a potential target. All eukaryotes contain a small binding protein called Rho GTPases. These are the Ras superfamilies in GTP-binding proteins.In 1985, the first Rho GTPases were found in human body, which were RhoA, B and C, respectively[22]. RHOB promotes proliferation and intrusion of melanoma [23], breast cancer [23-26] and colon cancer [27-29]. Whereas, it is still not very clear about the impact of RHOB on PTC in humans.. In the current study, we attempted to identify any inhibiting act of miR-223 in human PTCs and to clear the potential mechanisms involved. The results may help define the process of tumorigenesis, identify a potential biomarker for PTC progression, and determine if miR-223 may be Potential therapeutic targets for PTC a treatment site that is not obvious to PTC.

\section{Methods}

\section{Study subjects and patientorganized system specimens}

A general of 47 couples of PTC and close tissue specimens the source of collection is the patient undergoing surgery in Shengjing Hospital, it is an affiliated hospital of China Medical University, located in Shenyang. Tissue specimens must be stored in liquid nitrogen after separation and the temperature is limited to $-80^{\circ} \mathrm{C}$.Participants already need to sign a consent form before the study. This program has been adopted by the Ethics Committee of Shengjing Hospital of the Affiliated Hospital of China Medical University. The work must also be carried out under the World Medical Association Ethics Code (Helsinki Declaration). All the samples (including cancer and normal thyroid tissue) are diagnosed by three pathologists to confirm the histologic diagnosis.

\section{Cell culture and transient transfection}

Purchased human PTC cells and cell line BCPAP from Shanghai Chinese Academy of Sciences(Shanghai, China). The culture of BCPAP cells requires that the culture environment be RPMI 1640 medium with 10\% fetal calf serum (FBS; Gibco, USA). K1 cells were cultured in DMEM medium (Gibco, Grand Island, NY, USA) supplemented with $10 \%$ fetal bovine serum (FBS; Gibco, USA).MiR-223 mimics and negative-control (NC negative) were bought from Ibsbio (Shanghai, China). The overexpression vector and small interfering RNA (siRNA)for RHOB and the respective controls werepurchased from Ibsbio (Shanghai, China).From the manufacturer's instructions we can know to make lipofectamine 2000 (Invitrogen, USA) to transfect cells.

\section{Real-time measurement of the amount of reverse transcriptase polymerase (qRT-PCR)}

If we want to extract cell line cells and total RNA in tissues, we need to rely on TRIzol reagents. We can use the integrated miRNA qPCR kit (GeneCopoeia, Rockville, MD, USA) or the Thermo One-Step RT-PCR kit (Thermo Fisher Scientific) for real-time PCR for miRNA expression according to the manufacturer's instructions. The control gene U6 was applied as a command and for normalization. $2^{-\Delta \Delta C t}$ method was used to analyze relative expression. 


\section{Western blotting}

Tissue samples orRIPA causes disruption of cultured cells(Sigma-Aldrich) inclusioncomplete Mini Protease and Phosphatase Inhibit. A Bradford protein using the detection method of Bio-Rad Company of the United States to quantify number of proteinsin the lysed samples. The protein was separated by $8 \%$ sodium dodecyl sulfate-polyacrylamide gel electrophoresis and transferred to a polyvinylidene fluoride (PVDF) membrane by wet transfer (EMD microporous, USA). Primary antibodies used for blotting included an anti-Rhob antibody (1:100, mouse, BD, USA) and an anti-ß-actin antibody (1:2000, Abcam, USA).We can use the ECL Prime Western blotting reagent (Amersham, USA) to detect the signal and make the signal visible to us.

\section{MTT cell viability assays}

In vitro growth of BCPAPand K1 cells was assessed using an MTT Cell Proliferation Assay Kit (Invitrogen, USA)According to the manufacturer's agreement.In short, The BCPAP and K1 cells obtained are placed in a 96-well plate for culture. (5000 cells/well). Every 24 h, 10 mLof MTT stock solution incubate in the medium of each well for $4 \mathrm{~h}$ followed by reaction with sodium dodecyl sulfate (SDS)-HCl solution for $30 \mathrm{~min}$. The cells in the 96-well plate were then examined using a BioTek Synergy II microplate reader (BioTek, USA). The cell proliferation rates were determined according to the luminescence readings for each well at an optical density (OD) of $490 \mathrm{~nm}$.

\section{Cell migration and cell invasion assays}

Migration experiment inserts with a pore size of $8 \mu \mathrm{m}$ (Corning, USA),the ability of cell invasion can be judged by this method.BCPAPand $\mathrm{K} 1$ cells were sownplace in 6-well plates overnight. Following incubation at $37^{\circ} \mathrm{C}$ for $48 \mathrm{~h}$, the cells were trypsinized and counted. Then, $4 \times 10^{4}$ of the resuspended cells were seeded into the top chambers of the Transwell inserts. The medium to be cultured in the lower chamber is RPMI 1640 medium or DMEM medium supplemented with $20 \%$ fetal bovine serum. When $48 \mathrm{~h}$ have passed, the cells remaining on the upper membrane were removed. The cells that migrated to the lower surface of the membrane were fixed, then stained with $0.5 \%$ crystal violet reagent, and finally recorded by a microscope placed under the microscope. Repeat the above experiment three times

\section{Dual-luciferase reporter assay}

According to the manufacturer's instructions, we can use the dual luciferase reporter assay to speculate on luciferase activity.Implanted miR-223 mimics or BCPAP and K1 cells used for reverse control were placed in 96-well plates. When $12 \mathrm{~h}$ have passed, the cells were furtherinfection $50 \mathrm{ng}$ pGL3-WT-3'-UTRRhob or pGL3-Mut-3'-UTR-Rhob using Lipofectamine 2000 reagent. When it has been cultivated for 24 hours, the luminescence was discovered using a Dual-Luciferase Reporter assay system (Promega, USA).

\section{Apoptosis assays}


The apoptosisof BCPAP or K1 cells were detection by flow cell flow meter. Briefly, for Annexin V dyeing, 5 $\mu \mathrm{L}$ phycoerythrin-Annexin $\mathrm{V}, 5 \mu \mathrm{L}$ propidium iodization(BD Pharmingen), and $300 \mu \mathrm{L} 1 \times$ binding cushion were incubatedwith the cells allow to stand for 15 minutes at room temperature. The samples were then analysed within $1 \mathrm{~h}$ of staining flow cytometry (FACS Canto II, BD Biosciences) was used. Data processing is performed by FlowJo software.The test were repeated three times.

\section{Colorimetric caspase- 3 assays}

BCPAP and K1 splitting cells with RIPA bufferand then their protein chromas were resoluted by Bradford assay. Every $100 \mu \mathrm{g}$ of protein was dealed with $10 \mu \mathrm{L}$ Ac-DEVD-pNA (Abcam, USA) and incubate for 2 hours at 37 degrees Celsius. The absorbance at $405 \mathrm{~mm}$ was measured by a microplate reader (Bio-Tek instrument).

\section{Statistical Analysis}

The above experiments were performed three times. SPSS 17.0 software (SPSS, Inc., Chicago, USA) was employed to perform the statistical analyses. The representation of the data is: mean \pm standard deviation. Statistical differences can be analyzed using Student's $t$ test or one-way variance. $P<0.05$ is a statistically significant difference.

\section{Results}

\section{Aberrant expression of miR-223 in human PTC organizations}

To evaluate the utterance of miR-223 in papillary thyroid carcinoma (PTCs), 47 paired PTC and adjacent non-tumor tissue samples were examinedusingqRT-PCR. Thirty-eightof the PTC specimens were found to have lower miR-223 expression than the adjacent non-tumor tissue specimens (Figure 1A).We alsoobserved that PTC specimens exhibited lower levels of miR-223 expressionthan the paired adjacent non-tumor tissues (Figure 1B).

\section{MiR-223 may have inhibited PTC progression and metastasis in patients}

After determining the utterance of miR-233 in PTC organizations, we then analyzed the correlation between miR-223 and the clinicopathological parameterscan be obtained from clinical experience. We can get the results from Table 1. The expression of miR-233 is not affected by age, sex, and tumor size., multicentricity, or extrathyroidal invasion. However, lower miR-223 levels were detected in patients with advanced TNM stages and with cervical lymph node metastasis. All the above results reflect that the evolution and transfer of PTC may be affected by miR-233. 
Overexpression of miR-223 in PTC cells restrained proliferation and migration and promoted apoptosis PTC cells in vitro

MTT assays were used to evaluate the effect of overexpression of miR-223 on the proliferation of BCPAP and $\mathrm{K} 1$ cells. We transientlytransfer infection BCPAP and K1 cells with miR-223 mimic or negative control (Figure 2A). The forced overexpression of miR-223 inhibited the development of BCPAP and K1 cells emulated to that observed in negative control cells in a time-dependent manner (Figure 2B). The migration potential of BCPAP and K1 cells overexpressing miR-223 can be identified by transwell migration assay.Forced overexpression of miR-223lead todecreased cell invasion (BCPAP cells, $\mathrm{P}=0.035$; $\mathrm{K} 1$ cells, $\mathrm{P}=0.022$;Figure $2 \mathrm{C}$ ). Tofix the effect of miR-223 overexpression on cell apoptosis, Annexin- $\mathrm{V}$ staining was performed. Overexpression of miR-223 in PTC cells significantly promoted cell apoptosis(Fig. 2D). Similar results were observed for the colorimetric caspase 3 assays (Fig. $2 \mathrm{E})$.Collectively, these dataindicated that the overexpression of miR-223 inhibits proliferation and invasion of PTC, accelerates cell death in vitro.

\section{MiR-223 directly inhibited RHOB expression in vitro}

Based on the bioinformatics analyses (miRWalk,TargetScan, and PicTar), RHOB was predictedto bea potential mark of miR-223. MiR-223 overexpression in PTC cellswas related to a significantreduce in RHOB expression beside that in the negative control cells (Figure 3A). Moreover,The relationship between $\mathrm{miR}$ and $\mathrm{RHOB}$ can be judged by measuring the luciferase reporter gene. Construct a cell that can transfer the infection, which contains the RHOB wild type or the 3'-UTR luciferase reporter plasmid (as shown in Figure 3B). When the wild-type RHOB 3'-UTR plasmid was transfected with the miR-223 mimetic, the activity was significantly inhibited. However, the amount of miR-223 contained did not affect the luciferase activity of the reporter gene containing the mutant 3'-UTRs (as shown in Figure 3C). From the above results can be derived that RHOB was a first-hand mark of miR-223 in PTC.

\section{RHOB overexpression reversed the result of miR-223 overexpression}

To promotedetermine the RHOB-mediated result of miR-223 in PTC, a RHO-specific overexpression vector was transfected into BCPAP and K1 cells overexpressing miR-223 (Fig. 4A), which restored RHOB expression ( $59.22 \pm 4.58$ vs. $30.12 \pm 3.25$ in BCPAP transfected only by mocks, $P=0.028 ; 47.71 \pm 2.91$ vs. $28.58 \pm 2.21$ in $\mathrm{K} 1$ cells transfected with mimic alone, $\mathrm{P}=0.048$ ) Wediscovered that $\mathrm{RHOB}$ overexpression restored the inhibitoryresult of miR-223 on proliferation and invasion in miR-223-overexpression cells (Fig. 4B and $4 C$ ). A time-dependent increase in cell proliferation was observed in the BCPAP and K1 cells also overexpressing RHOB compared tothat in BCPAP and K1 cells overexpressing miR-223 $(10.8 \pm 0.7,14.2 \pm$ $2.1,24.5 \pm 3.7$, and $39.4 \pm 5.1 \%$ at $24,48,72$, and $96 \mathrm{~h}$ in BCPAP cells, respectively, $\mathrm{P}=0.031 ; 4.5 \pm 0.3$, $17.4 \pm 2.5,22.2 \pm 3.1$, and $30.7 \pm 4.3 \%$ at $24,48,72$, and $96 \mathrm{~h}$ in BCPAP cells, respectively, $\mathrm{P}=0.044$ ). 
Furthermore, RHOB overexpression obviously alleviated apoptosis (Fig. 4D and 4E). These data suggested that miR-223 inhibited PTC progression by inhibiting RHOB.

\section{Discussion}

PTC is common in all diagnosed thyroid cancers, accounting for $80 \%$ of the rate [22]. Although PTC patients always have a good prognosis for overall survival, some patients with advanced stage disease have a poor quality of life. It is therefore important to determine the mechanism ofprogression for PTC [23].

MiR-223 has been reported to have an inhibitory effect in many solid malignancies. Fabris et al. highlightedmiR-223 as a tumor inhibitor in breast cancer [14], Eto et al. have reportedmiR-223 inhibits gastric cancer progression [15], and Dong et al. have shown that miR-223 is used to control the increase of cell death rate to control the increase of liver cancer cells [18]. Furthermore, several researches have found that miR-223 repression colon cancer progression [19-21].In the latest research, we observed decreased act of miR-223 in 38 paired PTC tissue specimens. We also studied the relationship between miR-223 and clinical pathological parameters of PTC, and found that there is a certain relationship between lower miR-223 level and late TNM stage and cervical metastasis. Moreover, BCPAP and K1 cells were used to investigate the effect of aberrant act of miR-223 in PTC cells. We demonstrated that miR223 suppression PTC cell increase the amount, migration, and invasion and promoted apoptosis. So we can get miR-223 to inhibit the progression of PTC.

To reveal the molecular mechanisms of miR-223 in PTC progression, we can speculate on the target of miR-223 with the help of TargetScan, PicTar and miRanda online tools, and further find RHOB as a potential target.All eukaryotes have a small GTP/GDP binding protein called Rho GTPases, which is a GTP-binding protein in the Ras superfamily. RhoA, RhoB and RhoC were the first Rho GTPases discovered in humans in 1985 [22]. Huang et al. showed that gluco-corticoids can increase the amount of Rhorelated kinase secretion by $50 \%$, and can also have a positive effect on the migration, invasion and metastasis of melanoma [23]. Moreover, it has been revealed that RHOB promotes growth and invasion of breast cancer cells [24-26] and RHOB promotes colon cancer progression [29-31]. In the latest research, we also used the BCPAP and K1 cells to investigate the relationship between miR-223 and RHOB. MiR-223 overexpression is associated with significant inhibition of RHOB content. Furthermore, We can get from the luciferase test report that miR-223 was able to bind RHOB 3'-UTR. It has a certain influence on its stability, which eventually leads to a decrease in RHOB content. Furthermore, we proved that the overexpression of RHOB deteriorate the acts of miR-223 overexpression on cell proliferation, invasion, and apoptosis.

Overall, our results showed that the aberrant miR-223/RHOB expression was related to PTC progression. The miR-223 inhibition caused RHOB overexpression and cancer progression. Thence, miR-223 is perhaps a potential therapeutic mark for PTC. 


\section{Declarations}

\section{Ethics approval and consent to participate}

The research had been supported by the Ethics Committee of Shengjing Hospital. Relevant clinical information was gathered from patients' records and informed written consent had been gained. The papillary thyroid carcinoma cell lines BCPAP and K1 were obtained from Cell bank of typical culture preservation Committee of Chinese Academy of Sciences, and did not require ethics approval for their use in this study.

\section{Consent to publishcation}

Not applicable

\section{Availability of data and materials}

The datasets used or analysed during the current study are available from the corresponding author on reasonable request.

\section{Authors' Contributions}

XZ designed the study and drafted the manuscript. WJ reviewed the article. WZ condected the experiments. All authors have read and approved the final manuscript.

\section{Competing interests}

The authors declare there isn't any conflict of interest.

\section{Funding}

The National Natural Science Foundation of China gave a lot of support to the paper (grant No.81302364).

\section{Acknowledgements}


Dr. Yue Li, Dr. Zhe Wang and Dr. Jinping Gao confirmed the histologic diagnosis of all the cancer and normal thyroid tissue samples.

\section{References}

1. Morris LG, Tuttle RM, Davies L: Changing Trends in the Incidence of Thyroid Cancer in the United States. JAMA otolaryngology- head \& neck surgery 2016, 142(7):709-711.

2. Jemal A, Siegel R, Xu J, Ward E: Cancer statistics, 2010. CA: a cancer journal for clinicians 2010, 60(5):277-300.

3. Pellegriti G, Frasca F, Regalbuto C, Squatrito S, Vigneri R: Worldwide increasing incidence of thyroid cancer: update on epidemiology and risk factors. Journal of cancer epidemiology 2013, 2013:965212.

4. Landa I, Ibrahimpasic T, Boucai L, Sinha R, Knauf JA, Shah RH, Dogan S, Ricarte-Filho JC, Krishnamoorthy GP, Xu B et al: Genomic and transcriptomic hallmarks of poorly differentiated and anaplastic thyroid cancers. The Journal of clinical investigation 2016, 126(3):1052-1066.

5. Denli AM, Tops BB, Plasterk RH, Ketting RF, Hannon GJ: Processing of primary microRNAs by the Microprocessor complex. Nature 2004, 432(7014):231-235.

6. Mo YY: MicroRNA regulatory networks and human disease. Cellular and molecular life sciences : CMLS 2012, 69(21):3529-3531.

7. Rodriguez AE, Hernandez JA, Benito R, Gutierrez NC, Garcia JL, Hernandez-Sanchez M, Risueno A, Sarasquete ME, Ferminan E, Fisac R et al: Molecular characterization of chronic lymphocytic leukemia patients with a high number of losses in 13q14. PloS one 2012, 7(11):e48485.

8. Fazi F, Racanicchi S, Zardo G, Starnes LM, Mancini M, Travaglini L, Diverio D, Ammatuna E, Cimino G, Lo-Coco $\mathrm{F}$ et al: Epigenetic silencing of the myelopoiesis regulator microRNA-223 by the AML1/ETO oncoprotein. Cancer cell 2007, 12(5):457-466.

9. Mavrakis KJ, Van Der Meulen J, Wolfe AL, Liu X, Mets E, Taghon T, Khan AA, Setty M, Rondou P, Vandenberghe $\mathrm{P}$ et al: A cooperative microRNA-tumor suppressor gene network in acute T-cell lymphoblastic leukemia (T-ALL). Nature genetics 2011, 43(7):673-678.

10. Pulikkan JA, Dengler V, Peramangalam PS, Peer Zada AA, Muller-Tidow C, Bohlander SK, Tenen DG, Behre G: Cell-cycle regulator E2F1 and microRNA-223 comprise an autoregulatory negative feedback loop in acute myeloid leukemia. Blood 2010, 115(9):1768-1778.

11. Rainer J, Ploner C, Jesacher S, Ploner A, Eduardoff M, Mansha M, Wasim M, Panzer-Grumayer R, Trajanoski Z, Niederegger $\mathrm{H}$ et al: Glucocorticoid-regulated microRNAs and mirtrons in acute lymphoblastic leukemia. Leukemia 2009, 23(4):746-752.

12. Xu Y, Sengupta T, Kukreja L, Minella AC: MicroRNA-223 regulates cyclin E activity by modulating expression of F-box and WD-40 domain protein 7. The Journal of biological chemistry 2010, 285(45):34439-34446. 
13. Fabris L, Berton S, Citron F, D'Andrea S, Segatto I, Nicoloso MS, Massarut S, Armenia J, Zafarana G, Rossi $S$ et al: Radiotherapy-induced miR-223 prevents relapse of breast cancer by targeting the EGF pathway. Oncogene 2016, 35(37):4914-4926.

14. Jia CY, Li HH, Zhu XC, Dong YW, Fu D, Zhao QL, Wu W, Wu XZ: MiR-223 suppresses cell proliferation by targeting IGF-1R. PloS one 2011, 6(11):e27008.

15. Eto $K$, Iwatsuki M, Watanabe M, Ishimoto T, Ida S, Imamura Y, Iwagami S, Baba Y, Sakamoto $Y$, Miyamoto $Y$ et al: The sensitivity of gastric cancer to trastuzumab is regulated by the miR223/FBXW7 pathway. International journal of cancer 2015, 136(7):1537-1545.

16. Zhou X, Jin W, Jia H, Yan J, Zhang G: MiR-223 promotes the cisplatin resistance of human gastric cancer cells via regulating cell cycle by targeting FBXW7. Journal of experimental \& clinical cancer research : CR 2015, 34:28.

17. Bhattacharya S, Steele R, Shrivastava S, Chakraborty S, Di Bisceglie AM, Ray RB: Serum miR-30e and miR-223 as Novel Noninvasive Biomarkers for Hepatocellular Carcinoma. The American journal of pathology 2016, 186(2):242-247.

18. Dong Z, Qi R, Guo X, Zhao X, Li Y, Zeng Z, Bai W, Chang X, Hao L, Chen Y et al: MiR-223 modulates hepatocellular carcinoma cell proliferation through promoting apoptosis via the Rab1-mediated mTOR activation. Biochemical and biophysical research communications 2017, 483(1):630-637.

19. Liu L, Zhang C, Li X, Sun W, Qin S, Qin L, Wang X: miR-223 promotes colon cancer by directly targeting p120 catenin. Oncotarget 2017, 8(38):63764-63779.

20. Zekri AR, Youssef AS, Lotfy MM, Gabr R, Ahmed OS, Nassar A, Hussein N, Omran D, Medhat E, Eid S et al: Circulating Serum miRNAs as Diagnostic Markers for Colorectal Cancer. PloS one 2016, 11(5): $\mathrm{e} 0154130$.

21. Zhu Y, Xu A, Li J, Fu J, Wang G, Yang Y, Cui L, Sun J: Fecal miR-29a and miR-224 as the noninvasive biomarkers for colorectal cancer. Cancer biomarkers : section A of Disease markers 2016, 16(2):259264.

22. Madaule P, Axel R: A novel ras-related gene family. Cell 1985, 41(1):31-40.

23. Huang GX, Wang Y, Su J, Zhou P, Li B, Yin LJ, Lu J: Up-regulation of Rho-associated kinase 1/2 by glucocorticoids promotes migration, invasion and metastasis of melanoma. Cancer letters 2017, 410:1-11.

24. Casteel DE, Turner S, Schwappacher R, Rangaswami H, Su-Yuo J, Zhuang S, Boss GR, Pilz RB: Rho isoform-specific interaction with IQGAP1 promotes breast cancer cell proliferation and migration. The Journal of biological chemistry 2012, 287(45):38367-38378.

25. Medale-Giamarchi C, Lajoie-Mazenc I, Malissein E, Meunier E, Couderc B, Berge Y, Filleron T, Keller L, Marty $\mathrm{C}$, Lacroix-Triki $\mathrm{M}$ et al: RhoB modifies estrogen responses in breast cancer cells by influencing expression of the estrogen receptor. Breast cancer research : BCR 2013, 15(1):R6.

26. Kuang Y, Nie YJ: Exploration of the regulatory effect of miR-21 on breast cancer cell line proliferation and invasion as well as the downstream target genes. Asian Pacific journal of tropical medicine 2016, 9(5):470-473. 
27. Kim DM, Won M, Chung CS, Kim S, Yim HJ, Jung SH, Jeong S: JNK-mediated transcriptional upregulation of RhoB is critical for apoptosis of HCT-116 colon cancer cells by a novel diarylsulfonylurea derivative. Apoptosis : an international journal on programmed cell death 2010, 15(12):1540-1548.

28. Suboj P, Babykutty S, Valiyaparambil Gopi DR, Nair RS, Srinivas P, Gopala S: Aloe emodin inhibits colon cancer cell migration/angiogenesis by downregulating MMP-2/9, RhoB and VEGF via reduced DNA binding activity of NF-kappaB. European journal of pharmaceutical sciences : official journal of the European Federation for Pharmaceutical Sciences 2012, 45(5):581-591.

29. Xiao H, Zhang Q, Lin Y, Reddy BS, Yang CS: Combination of atorvastatin and celecoxib synergistically induces cell cycle arrest and apoptosis in colon cancer cells. International journal of cancer 2008, 122(9):2115-2124.

30. McCaffrey JC: Aerodigestive tract invasion by well-differentiated thyroid carcinoma: diagnosis, management, prognosis, and biology. The Laryngoscope 2006, 116(1):1-11.

31. McLeod DS, Sawka AM, Cooper DS: Controversies in primary treatment of low-risk papillary thyroid cancer. Lancet 2013, 381(9871):1046-1057.

\section{Table}

Table 1. Correlation of miR-223 expression with clinicopathological factors of PTC patients 


\begin{tabular}{lccc}
\hline Parameters & Patients & miR-223 & P \\
\hline Total & 47 & & \\
Gender & & & 0.489 \\
Male & $10(21.3)$ & $3.09 \pm 1.52$ & \\
Female & $37(78.7)$ & $3.35 \pm 1.88$ & \\
\hline & & & 0.624 \\
Age $(\mathbf{Y})$ & & & \\
$\geq 45$ & $29(61.7)$ & $3.12 \pm 1.79$ & \\
$<45$ & $18(38.3)$ & $3.31 \pm 1.58$ & \\
\hline
\end{tabular}

\section{Tumor size,cm}

$\geq 2$
$<2$

$19(40.4)$

0.115

Extrathyroidal invasion $28(59.6)$

$3.03 \pm 1.82$ $3.52 \pm 1.63$

\begin{tabular}{llll} 
Yes & $12(25.5)$ & $3.05 \pm 2.16$ & 0.087 \\
No & $35(74.5)$ & $3.88 \pm 1.54$ & \\
\hline
\end{tabular}

\begin{tabular}{llll} 
Multicentricity & & & 0.074 \\
Yes & $13(27.6)$ & $3.01 \pm 2.04$ & \\
No & $34(72.4)$ & $3.92 \pm 1.80$ & \\
\hline & & & \\
Cervical metastasis status & & & 0.018 \\
$\mathrm{~N}+$ & $21(44.7)$ & $2.09 \pm 1.45$ & \\
$\mathrm{~N}-$ & $26(55.3)$ & $4.35 \pm 1.99$ & \\
\hline
\end{tabular}

TNM stages

\begin{tabular}{lrr} 
I/II & $29(61.7)$ & $4.16 \pm 1.86$ \\
III/IV & $18(38.3)$ & $2.17 \pm 1.57$ \\
\hline Note: Values in parentheses represent percentages & \\
\hline
\end{tabular}

0.032

\section{Figures}



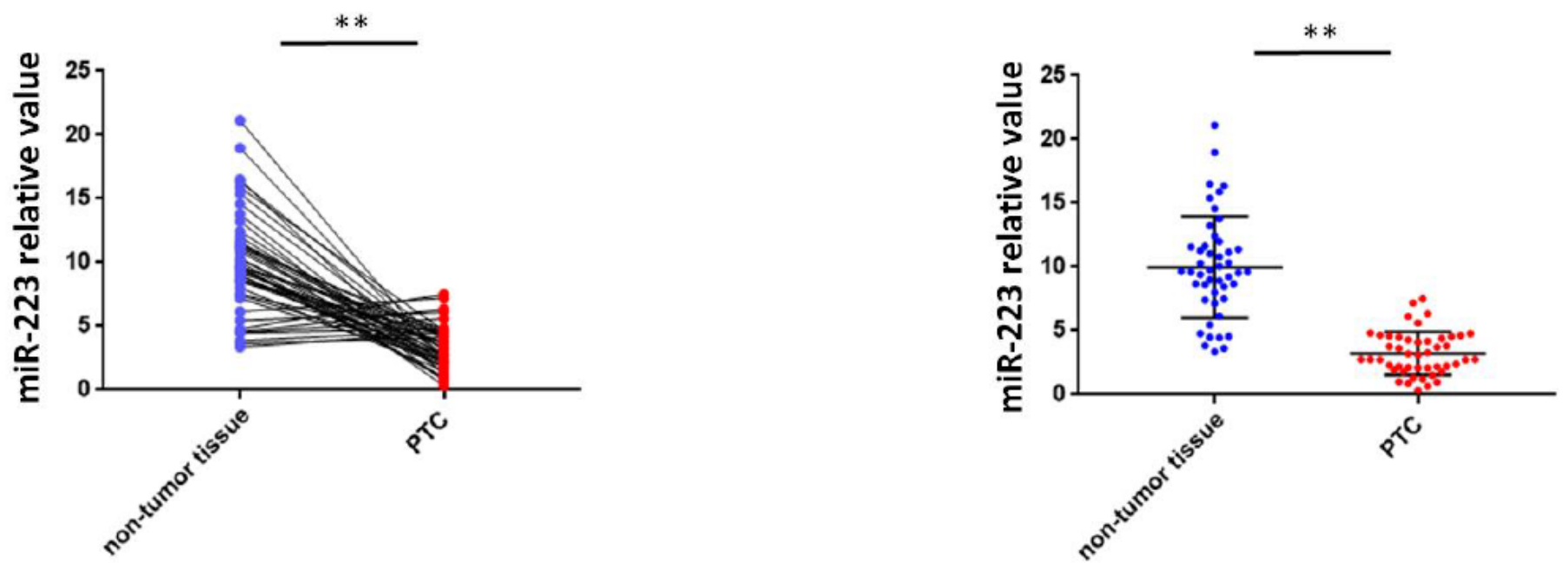

\section{Figure 1}

Abnormal expression of miR-223 in PTC specimens. (A) Quantification of the process of reverse transcription polymerase reaction(qRT-PCR) analysis of miR-223expression in 47 paired PTC and adjacent non-tumor tissues. Of the 47 PTC specimens, 38 had lower miR-223 expression than the control. Statistical analysis is carried out by t-test method, and the analysis is performed after logarithmic transformation. $(P=0.002)$.Each set of experiments was performed three times. The repetition of a creature is represented by a dot. (B) qRT-PCR split understanding of miR-223 deliverance in PTC and control samples $(3.23 \pm 1.71$ vs. $10.00 \pm 3.98$. Perform log transformation on data for split understanding $(P=0.003)$. MiR-223 deliverance was 3.1-twice as much adjacent non-tumor tissue samples than in the PTC specimens. The U6 gene was used as a positive control and for normalization. 
A

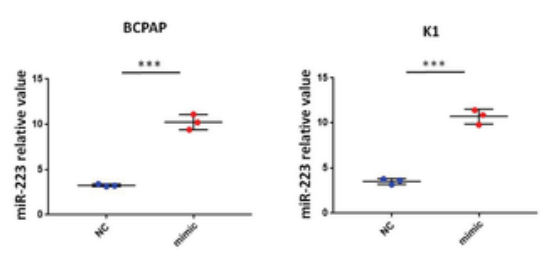

B
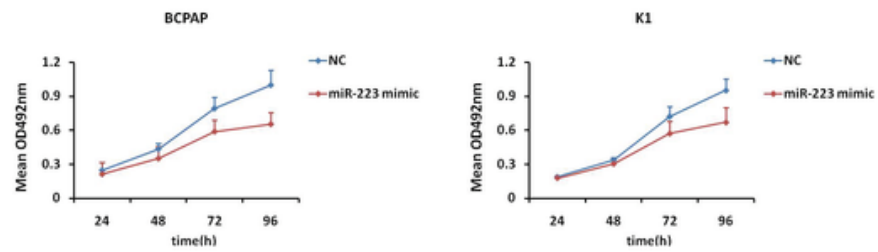

C
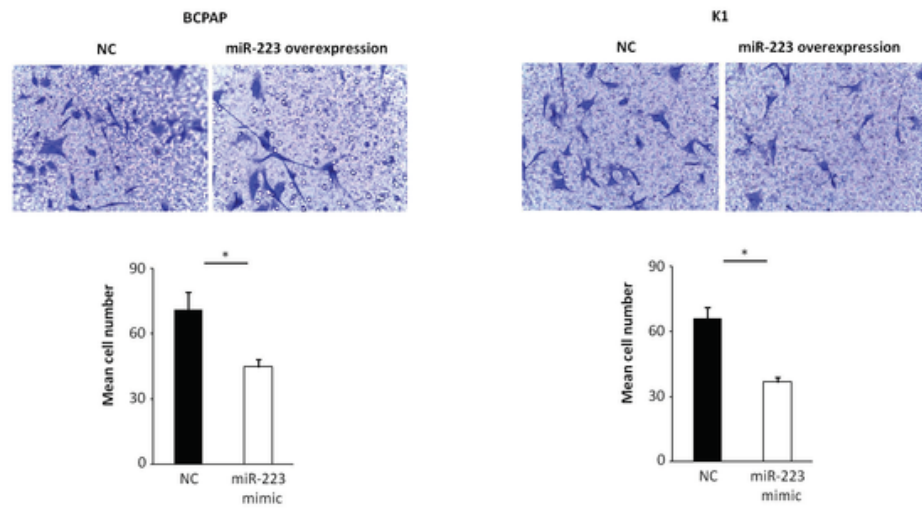

D
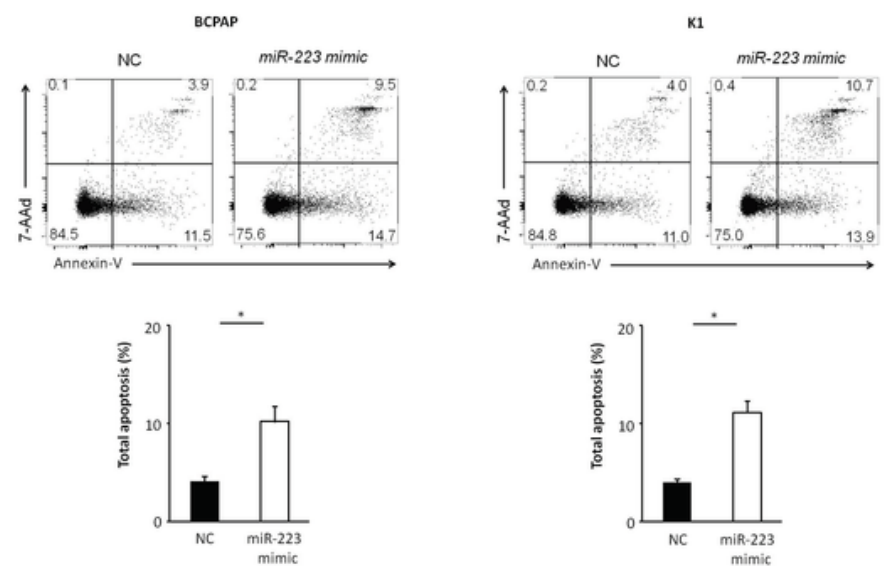

E
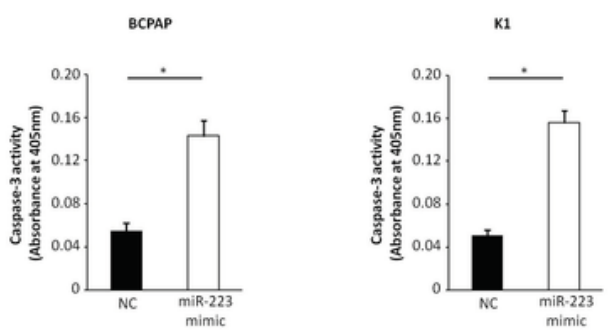

Figure 2

\section{Figure 2}

Influencet of miR-223 on PTC cell proliferation, invasion, and apoptosis. (A) BCPAP and K1 cells temporarily transfected with miR-233 mimics or negative control (BCPAP: $10.24 \pm 0.49$ vs.3.25 \pm 0.08 [bridlel], $P=0.033 ; \mathrm{K} 1: 10.70 \pm 0.43$ vs.3.51 \pm 0.18 [bridlel], $P=0.045)$. (B) Cell survival rates determined by MTT assays in miR-223-overexpressed and control BCPAP and K1 cells. Decline with time was found in the cell rate of increase in cell number of the miR-223-overexpression cells (BCPAP cells: $13.06 \% \pm 1.1$, 
$19.1 \% \pm 1.9,25.8 \% \pm 2.5$, and $34.6 \% \pm 4.1$ at $24,48,72$, and $96 \mathrm{~h}$, separately, $\mathrm{P}=0.026 ; \mathrm{K} 1$ cells: $6.4 \% \pm$ $0.5,10.1 \% \pm 1.1,20.7 \% \pm 1.5$, and $29.6 \% \pm 3.2$ at $24,48,72$, and $96 \mathrm{~h}$, separately, $P=0.046$ ). (C) Deputation photographs of Transwell aggressive attacks on miR-223 overexpression and negative effects on BCPAP and K1 cells (upper; magnifying power 200) and their quantitative analysis (bottom). (D) Deputypicture and proportion of cell-autonomous ordered death of BCPAP and K1 cells with miR-223overexpression or negative bridle ( ${ }^{\mathrm{P}}=0.039$ and 0.021 for BCPAP and $\mathrm{K} 1$ cells respectively). ( $\mathrm{E}$ ) Caspase- 3 activity in BCPAP and K1 cells with miR-223-overexpression or negative bridle cells ( $\mathrm{P}=0.036$ and 0.018 for BCPAP and K1 cells respectively). Each set of experiments was done three times. Dots delegatetese ditto. 
A

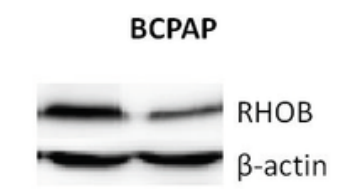

K1
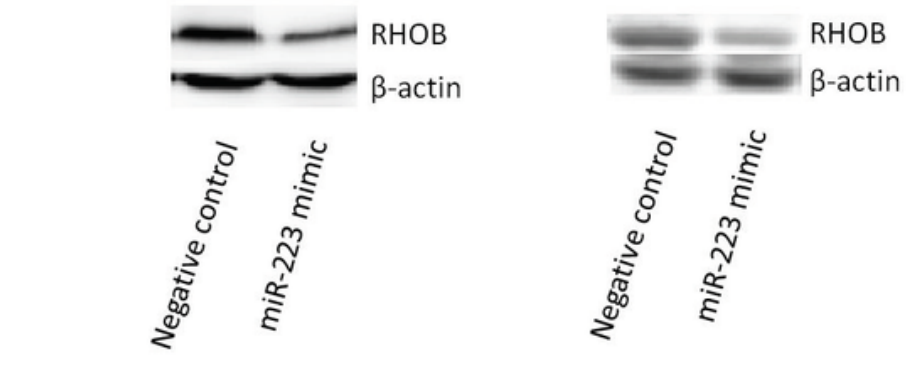

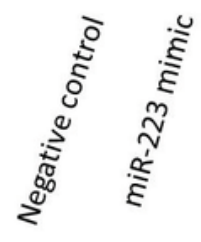

B
RHOB 3' UTR-WT $5^{\prime}$ ...UUUAUUUUUUAAAUAAACUGACA...
hsa-miR-223 $\quad 3^{\prime}$
| | | ||
ACCCCAUAAACUGU--------UUGACUGU

RHOB 3' UTR-Mutant $\quad 5$ '

...UUAUAAAUUUAAAUAUUGACUGA...

C

BCPAP

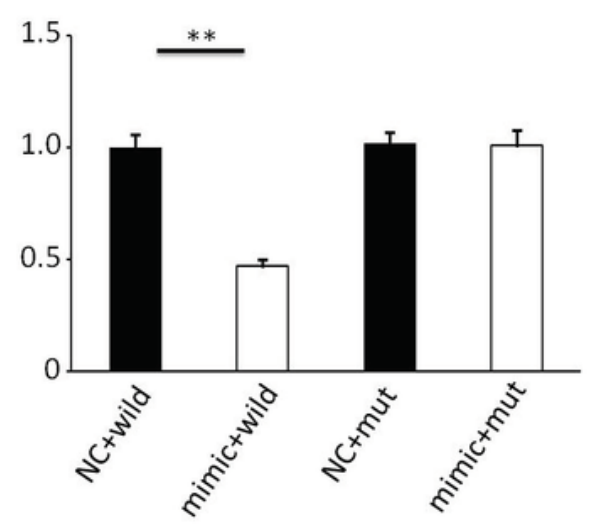

K1

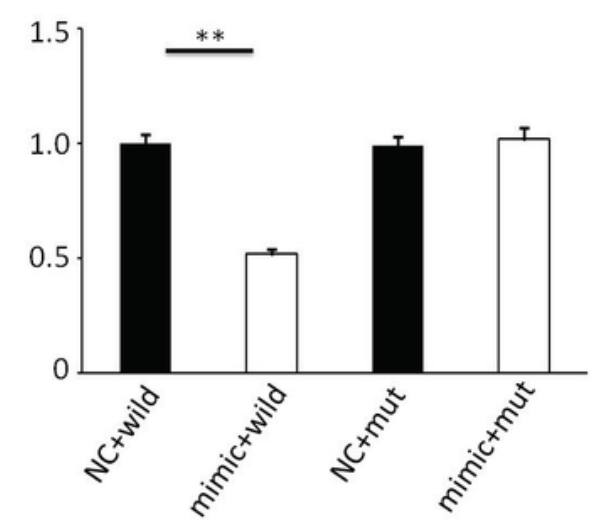

\section{Figure 3}

\section{Figure 3}

RHOB was a direct target of miR-223 in PTC. (A) Analysis of representative western blot and RHOB proteins by miR-223 simulation or negative comparison analysis of BCPAP and K1 cells (BCPAP: $78.33 \pm$ 6.45 vs. $33.87 \pm 3.52, P=0.022 ; K 1: 61.98 \pm 3.22$ vs. $29.65 \pm 2.38, P=0.040)$. $\beta$-actin was used as a bridle. (B) miR-223 straight from the shoulder interacted with the 3'-UTRs of RHOB. (C)After cotransfection with miR-223 mimic, the relative luciferase activity of the reporter plasmid containing the 
uncultivated-type RHOB 3'-UTR was significantly reduced. But the miR-223 level change did not produce an effect on the luciferase activity of the reporter plasmid with the RHOB mutant 3'-UTRs. These data are the mean $\pm S D$ of the results of three trials that do not interfere with each other. After the logarithmic transformation of the data by two-way analysis of variance, it is statistically organized and analyzed. ${ }^{*}, \mathrm{P}$ $=0.005$ and 0.009 for BCPAP and K1 cells, respectively. Dots delegatetese ditto.

A

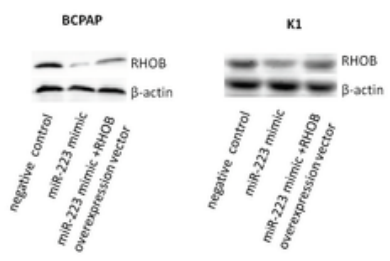

B

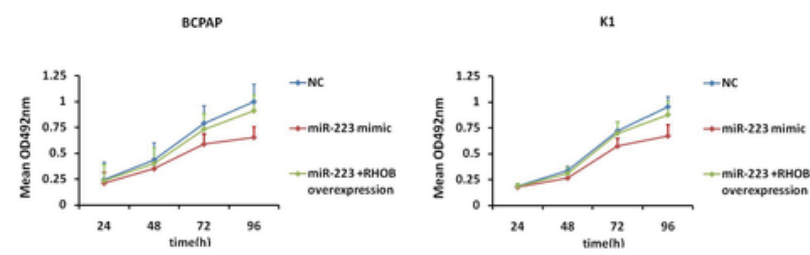

C
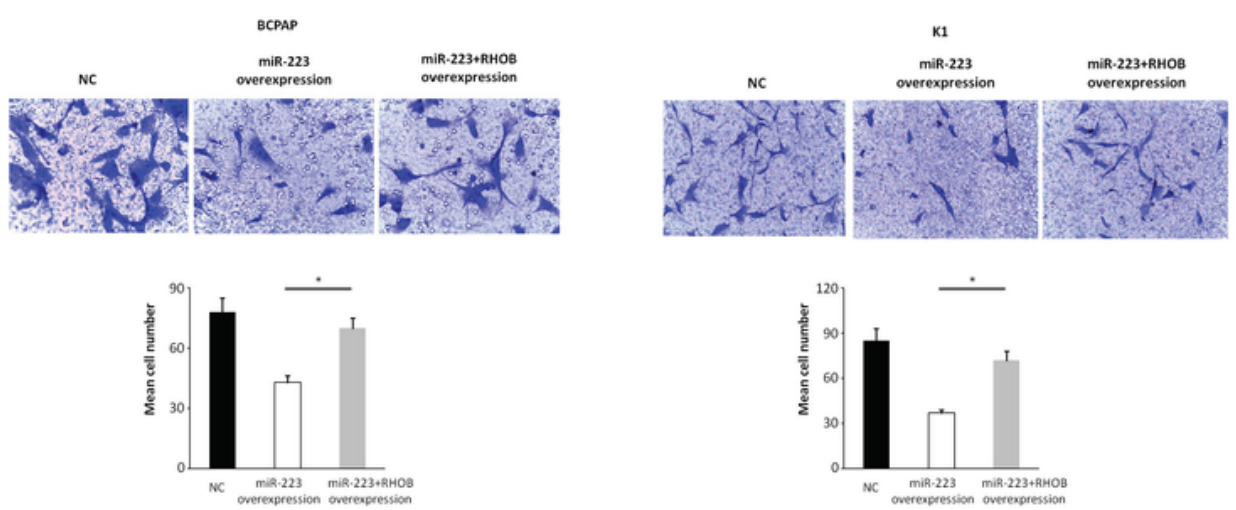

D
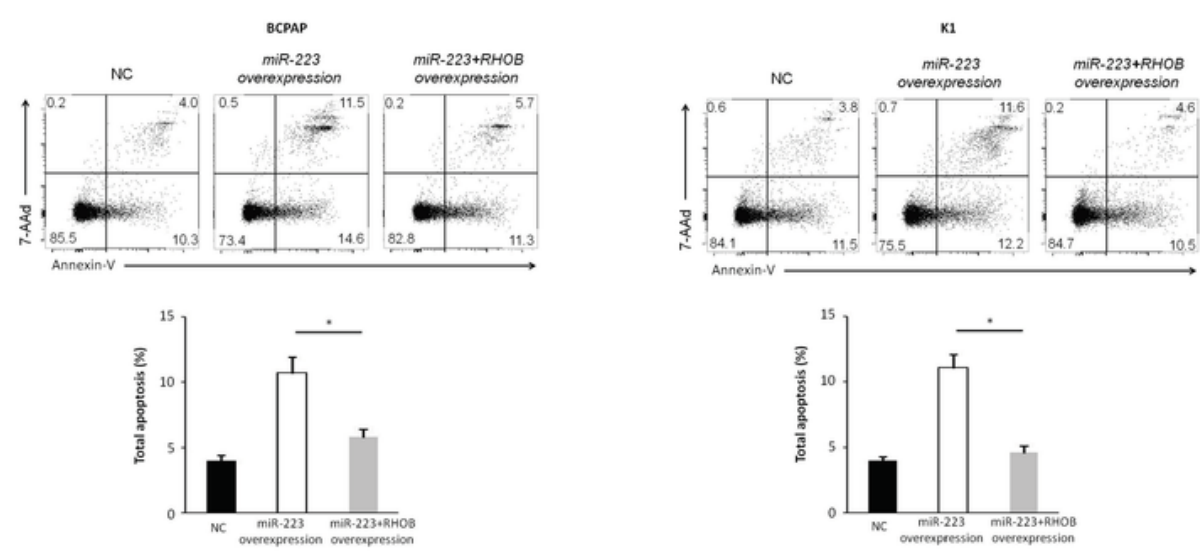

$E$
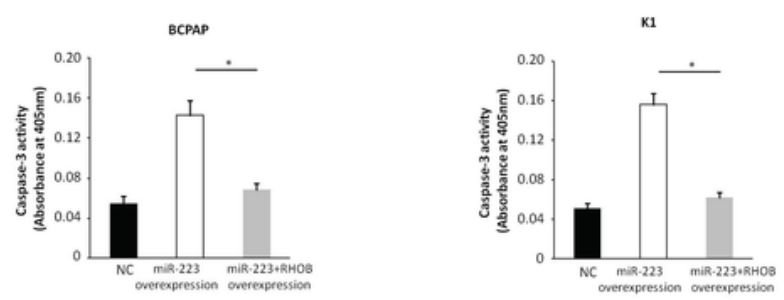

Figure 4

Figure 4 
RHOB overexpression restored the effects of miR-223(NC: negative control). (A) Typical western blot findings delivery that transfection of RHOB-overexpression carrier comtrastto restores the depression of RHOB after transfection with miR-223 mimic. (B) Value added rates of miR-223-overexpression BCPAP and $\mathrm{K} 1$ cells at different time points after RHOB overexpression. (C) Typical pictures (upper; magnifying power 200) of Transwell aggressive attacks of miR-223-overexpressing BCPAP and K1 cells with or without RHOB overexpression and analysis of specific quantities (bottom) ( ${ }^{*} \mathrm{P}=0.029$ and 0.042 for BCPAP and $\mathrm{K} 1$ cells, respectively). (D) Typical pictures showing the ratio of BCPAP and $\mathrm{K} 1$ cells in apoptosis after transfection with miR-223 mimic with and without RHOB overexpression ( ${ }^{*} \mathrm{P}=0.035$ and 0.020 for BCPAP and K1 cells, respectively). (E) Caspase-3 doings of BCPAP and K1 cells transfection with miR-223 mimic have and without RHOB over-deliverance ( ${ }^{*} \mathrm{P}=0.018$ and 0.013 for BCPAP and K1 cells, respectively). 